\title{
Agroecologia como estratégia política, produtiva e ambiental para a defesa de uma reforma agrária popular
}

\author{
Agroecology as a political, productive and environmental strategy for the defense of popular \\ land reform
}

La agroecología como estrategia política, productiva y ambiental para la defensa de la reforma agraria popular

\author{
Rafael Pereira Silva ${ }^{1}$ \\ José Rubens Laureano da Conceição ${ }^{2}$ \\ Cristiane Betanho ${ }^{3}$
}

RESUMO: Pode o movimento e a prática agroecológica se apresentar como um projeto de desenvolvimento, como estratégia política, produtiva e ambiental que, ao mesmo tempo, se contraponha à destruição ambiental e social promovida pelo latifúndio e evidencie a importância de uma reforma agrária popular? Para refletir sobre essa questão, foi proposta uma Roda de Conversa durante a V Jornada Universitária em Defesa da Reforma Agrária (JURA), que aconteceu entre 8 e 10 de maio de 2019, na Universidade Federal de Uberlândia. Os participantes entenderam que a agroecologia, ao se contrapor ao modelo vigente, supera a ideia de ser somente uma alternativa para produzir alimentos, e busca a transformação da sociedade de forma a garantir melhores condições de vida às pessoas do campo e da cidade. Nesse processo, a reforma agrária pode ser conhecida pelo seu real lado, a partir do reconhecimento dos trabalhadores que lutam pelo direito a terra, por um meio ambiente preservado e relações sociais justas para todos, sem as mistificações da mídia hegemônica.

Palavras-chave: Agroecologia. Reforma Agrária Popular. Reconhecimento Social.

ABSTRACT: Can the agroecological movement and practice be referred to as a development project, political, productive and environmental strategy in opposition to the environmental and social destruction promoted by the latifundium and highlights the importance of a popular land reform? To reflect this issue, a conversation circle was proposed during the 5th University Day in Defense of Agrarian Reform at the Federal University of Uberlândia, State of Minas Gerais, Brazil. Participants understood that agroecology, by opposing the current model, seeks to transform society and ensure better living conditions for people in the countryside and in the city. In this process, land reform can be seen from the recognition of workers who fight for the right to land, for a preserved environment and fair social relations, without the mystification of the hegemonic media.

Keywords: Agroecology. Popular Land Reform. Social Recognition.

\footnotetext{
${ }^{1}$ Graduando em Engenharia Ambiental na Universidade Federal de Uberlândia, Minas Gerais, Brasil; bolsista do Centro de Incubação de Empreendimentos Populares Solidários (Cieps/PROEXC/UFU) (rafaelpereiraufu@gmail.com).

${ }^{2}$ Morador do Assentamento Celso Lúcio Moreira da Silva (Comunidade Carinhosa); membro da Cooperativa de Economia Popular Solidária da Agricultura Familiar, Reflorestamento e Agroecologia (COOPERSAFRA), incubada no Centro de Incubação de Empreendimentos Populares Solidários (Cieps/PROEXC/UFU) (jrlaureano.jrl@gmail.com).

${ }^{3}$ Doutora em Engenharia de Produção pela Universidade Federal de São Carlos, São Paulo, Brasil; professora associada da Faculdade de Gestão e Negócios da Universidade Federal de Uberlândia, Minas Gerais, Brasil; coordenadora do Centro de Incubação de Empreendimentos Populares Solidários (Cieps/PROEXC/UFU) (crisbetanho@ufu.br).
} 
RESUMEN: ¿Puede el movimiento y la práctica agroecológica presentarse como un proyecto de desarrollo, como una estrategia política, productiva y ambiental, que al mismo tiempo se opone a la destrucción ambiental y social promovida por el latifundio y destaca la importancia de una reforma agraria popular? Para reflexionar sobre este tema, se propuso una rueda de conversación durante el $5^{\circ}$ Día universitario en defensa de la reforma agraria, que tuvo lugar entre el 8 y el 10 de mayo de 2019, en la Universidad Federal de Uberlândia, Minas Gerais, Brasil. Los participantes entendieron que la agroecología, en oposición al modelo actual, supera la idea de ser solo una alternativa para producir alimentos, y busca la transformación de la sociedad para garantizar mejores condiciones de vida para las personas en el campo y en la ciudad. Así, la reforma agraria puede ser conocida por su lado real, basado en el reconocimiento de los trabajadores que luchan por el derecho a la tierra, por un medio ambiente preservado y relaciones sociales justas para todos, sin la mistificación de los medios de comunicación hegemónicos.

Palabras clave: Agroecología. Reforma agraria popular. Reconocimiento social.

\section{INTRODUÇÃO}

Para Furtado (1986, p. 93), “o Brasil é o único país das Américas criado, desde o início, pelo capitalismo comercial sob a forma de empresa agrícola", sendo a exportação a razão de ser da ocupação do território. Da plantation à industrialização (tardia e dependente) do país, a agricultura foi sempre vista a partir da lógica do latifúndio e da exportação.

Entre 1950 e 1964, os novos desafios econômicos e a necessidade de respostas mais qualificadas da agricultura - considerada à época obstáculo ao desenvolvimento da industrialização do país - impuseram a necessidade de modernizá-la. Segundo Kageyama (1993), caminhos propostos podem ser sintetizados em duas correntes teóricas: a modernização conservadora e a modernização estrutural. A primeira, por acreditar que o problema era institucional, advogava a expansão da agricultura pela intensificação da mecanização e do uso de fertilizantes e defensivos químicos, sendo que a questão social seria resolvida pela criação de empregos fora do setor agrícola. A segunda corrente, a modernização estrutural, defendia modificar a estrutura não apenas agrícola, mas agrária, ligada aos processos de transformação das relações de produção.

Com o golpe civil-militar de 1964, a corrente da modernização conservadora foi adotada e políticas públicas de crédito generosas implementadas para quem adotasse um pacote tecnológico que levaria a uma agricultura mais eficiente. Segundo Linhares e Silva (1999), a modernização da agricultura atendia, portanto, aos interesses industriais, primeiramente em termos de máquinas e implementos, para depois subordinar a produção agropecuária aos 
padrões agroindustriais, o que certamente beneficiava a conjugação dos interesses financeiros do grande capital multinacional.

Esse novo modelo, apesar de grandemente responsável pelo superávit fiscal do país, agravou o problema da distribuição da renda. Como salienta Graziano da Silva (1996), a pobreza é gerada por uma distribuição fortemente desigual dos fatores de produção, aliada ao modelo de desenvolvimento adotado, que privilegia a grande produção e a grande propriedade, possibilitando maior concentração da produção e dos capitais, promovendo a subordinação do trabalho ao capital.

Os produtores familiares que não possuem recursos para acompanhar a crescente tecnificação acabam tendo três saídas, a saber: a integração aos complexos agroindustriais, a produção para autoconsumo, ou utilização da terra apenas como local de moradia, deslocando-se os membros da família para o trabalho em centros urbanos ou no próprio meio rural, em atividades não agrícolas. De fato, o Censo Agropecuário indicou um aumento do número de estabelecimentos que admitiram usar agrotóxicos (20,4\% nos últimos 11 anos), sendo que $73 \%$ dos respondentes que afirmaram usar venenos possuíam menos de 20 hectares de área de lavouras (IBGE, 2017).

Os movimentos populares de luta pela reforma agrária no Brasil surgiram no agravamento da distribuição de renda advinda da adoção em massa do padrão do agronegócio. Desde a formação desses grupos, os assentamentos rurais buscaram estratégias para se opor a esse modelo de agricultura capitalista industrial, adotando o cooperativismo como principal forma de organização grupal. Como afirma Grzybowski (2004), apesar de muitos verem nos movimentos sociais apenas a questão social - a miséria e a pobreza - e não uma questão política, os movimentos sociais são potenciais democratizadores que podem contribuir para alterar correlações de força, auxiliando na edificação de outra ordem social.

Pode o movimento e a prática agroecológica se apresentar como um projeto de desenvolvimento, como estratégia política, produtiva e ambiental que, ao mesmo tempo, se contraponha à destruição ambiental e social promovida pelo latifúndio e evidencie a importância de uma reforma agrária popular? Para refletir sobre essa questão, foi proposta uma Roda de Conversa durante a V Jornada Universitária em Defesa da Reforma Agrária (JURA), que aconteceu entre 8 e 10 de maio de 2019 na Universidade Federal de Uberlândia, 
em conjunto com o $9^{\circ}$ Simpósio Internacional: O Estado e as Políticas Educacionais no Tempo Presente e a VII Feira Regional de Economia Popular Solidária.

Os autores propuseram um texto base para discussão, realizada no dia 9 de maio de 2019, ocasião em que os 17 participantes apresentaram suas considerações sobre o tema e suas contribuições para o avanço da temática. Os resultados estão sintetizados na seção a seguir.

\section{Agroecologia na defesa de uma reforma agrária popular}

O modelo padrão de agricultura que conhecemos hoje teve sua origem após a Segunda Guerra Mundial com a justificativa de que, ao se utilizar máquinas agrícolas e insumos, a produção ganharia proporções em larga escala, acabando com a fome no mundo. Esse processo, conhecido como Revolução Verde, expressão criada em 1966 por Willian Gown, aumentou significativamente a produção agrícola, mas impôs essas práticas à natureza e seus recursos naturais, gerando impactos graves ao ambiente, além da concentração de terra e capital (MOREIRA, 2000). Como salientaram os participantes da Roda de Conversa, não foi dado o direito de escolha aos agricultores, sequer foram compartilhadas informações sobre os impactos ambientais e socioeconômicos que seriam gerados com o uso intensivo e irresponsável do solo e da biodiversidade.

A produção em larga escala foi ratificada com o argumento de combate à fome, salientou um participante, e a modernização ganha aceitação e apoio de grande parte da população, sendo peça chave para a incorporação da indústria a esse processo, aprofundando as relações dos setores político e agrícola conservadores. Porém, como destacou outro participante, trouxe a modernização tecnológica para o campo, mas não reduziu com a fome no mundo, pois grande parte dessa produção nos países em desenvolvimento é destinada a outros países mais ricos, ou são alimentos ultraprocessados e produzidos em massa, sem respeito às culturas locais.

Acrescentando elementos à discussão, um trabalhador refletiu que esse movimento massificador gerou perdas genéticas e práticas, com o agricultor perdendo conhecimento das sementes e dos ciclos naturais de produção, alienando-se da terra. De fato, a modernização alterou por completo a estrutura agrária brasileira. Pequenos agricultores que não conseguiram se adaptar às novas condições, produziam muito pouco e com isso não competiam com a produção cada vez mais mecanizada e tecnológica de grandes corporações agrícolas. Muitos agricultores se endividaram com empréstimos bancários para tentar 
produzir em grande escala e acabaram perdendo suas terras como forma de pagamento de suas dívidas. Outros passaram a ser fornecedores de matérias primas para a agroindústria, a preços impostos pelos industriais e sem definir qualidade dos produtos (ANDRADES; GANIMI, 2007).

Como consequência do êxodo rural, a urbanização cresceu e vem crescendo ao longo dos anos em todas as regiões do país e do mundo, apresentando problemas sociais graves. Segundo o Relatório do Estado da Segurança Alimentar e Nutrição do Mundo, no ano de 2018, a Organização das Nações Unidas para a Alimentação e a Agricultura (FAO) registrou um aumento de pessoas passando fome, chegando ao número de 821 milhões de indivíduos (FAO, 2018). Os resultados de todo esse processo que ainda perdura nos dias de hoje traz reflexões sobre essa visão do modo de produção capitalista. Segundo os participantes da Roda de Conversa, esse sistema é contraditório em relação ao que defendem, pois atingiram a forma de produzir os alimentos de forma plena, mas ampliaram as desigualdades, as injustiças sociais e as agressões ao meio ambiente e seus recursos vitais na busca pelo lucro.

Com essa conjuntura, surgem os movimentos de luta pela reforma agrária, buscando democratizar a propriedade da terra na sociedade e garantir seu acesso por meio de estratégias diversas contra a monocultura e toda a base tecnológica que é imposta ao campo brasileiro. Desde o início dos movimentos, em todas as propostas de projetos para a reforma agrária, a questão ambiental foi discutida e incluída, tomando formas cada vez maiores dentro dos assentamentos ao longo dos anos.

A partir do apoio crescente de instituições de pesquisa, ambientalistas, professores, alunos e técnicos de extensão rural, os agricultores da reforma agrária tiveram acesso a diversos conhecimentos de produção sustentável de alimentos por meio de participações em congressos, intercâmbios e cursos, incorporando não só os princípios de um cuidado maior com o meio ambiente, mas também de novas relações sociais na agricultura. Como salientou um participante, houve a possibilidade de unir os conhecimentos dos agricultores aos acadêmicos, com ambas as partes ensinando e aprendendo. Nesse período de aprendizado, foram se reconhecendo protetores das sementes, da floresta, da água e da vida do solo, se contrapondo ao pacote tecnológico que é imposto no campo com o uso de insumos externos, agrotóxicos e mecanização agrícola. 
A ideia de um mundo rural sustentável começa a ser planejada e colocada em prática, apesar de serem pontuais e não ser a realidade de muitos assentamentos que ainda reproduzem modos de produção semelhantes à agricultura convencional (BORSATTO, 2011). Nesse sentido, a Agroecologia surge como uma nova alternativa de se fazer agricultura, ensinandonos que o ser humano é parte constituinte da natureza com a função de gerar vida, relacionando-se historicamente por meio do resgate da cultura e do saber popular, aliado às bases ambientais e sociais. A partir da experimentação, do diálogo e da confrontação, a Agroecologia se alia à realidade local, provendo diversidade não só de alimentos, mas de saberes, pessoas e suas práticas culturais.

Os agricultores experimentam uma nova forma de viver a partir e por meio da sua terra, sabendo respeitá-la com o cuidado e manejo das espécies. Isso ocorre a partir das práticas de conservação da biodiversidade com o cultivo em sistemas diversificados, como os agroflorestais. Com uma forma limpa de se fazer agricultura, os agricultores agroecológicos passaram a se organizar como grupos cooperativos e a criar uma nova conscientização social, estando implícitas as relações políticas e ideológicas dos movimentos sociais. Reconheceram a Agroecologia como uma possibilidade para a agricultura brasileira de modo a validar o movimento de reforma agrária como instrumento de justiça social no país.

\section{CONSIDERAÇÕES FINAIS}

A internalização do movimento agroecológico nos assentamentos não trouxe somente mudanças nos processos produtivos de alimentos, trouxe também centros de formação e escolas com uma educação no campo voltada aos princípios da Agroecologia como base de ensino para crianças e jovens que se viram capazes de mudar a realidade local em que vivem, conquistando seus espaços e ampliando os seus sonhos.

Assim, a Agroecologia se contrapõe por completo ao modelo de agricultura capitalista vigente, ultrapassando a ideia de ser somente uma alternativa de produzir alimentos, mas como forma de transformarmos a sociedade a partir dos processos de luta política dos movimentos populares, garantindo melhores condições de vida às pessoas do campo e da cidade.

Como salientaram os participantes da Roda de Conversa, na cidade, a Agroecologia se mostra no campo concreto a partir dos espaços das feiras, que são lócus de resiliência e troca de 
conhecimentos, de recuperação de saberes, de reconhecimento da origem da comida, das propriedades dos alimentos. São também os espaços em que a reforma agrária pode ser conhecida pelo seu real lado, a partir do reconhecimento dos trabalhadores que lutam a partir dessa realidade, sem as mistificações da mídia hegemônica.

É pela reforma agrária que a Agroecologia reconstrói novos coletivos e territórios, trazendo consigo a responsabilidade das famílias assentadas que assumem a tarefa de produzir alimentos saudáveis, com respeito ao meio ambiente e à sociedade, a partir da cooperação e das relações sociais que podem ser fortalecidas, aproximando o trabalhador urbano à realidade dos agricultores no campo, reforçando o reconhecimento da sociedade de que a reforma agrária é uma real necessidade do país para que tenhamos assegurado o direito à terra, um meio ambiente preservado e relações sociais justas para todos.

\section{REFERÊNCIAS}

ANDRADES, T. O.; GANIMI, R. N. Revolução Verde e a apropriação capitalista. CES Revista, Juiz de Fora, v. 21 p. 43-56, 2007. Disponível em: https://www.cesjf.br/revistas/cesrevista/edicoes/2007/revolucao_verde.pdf. Acesso em: 20 jan. 2020.

BORSATTO, R. S. A agroecologia e sua apropriação pelo Movimento dos Trabalhadores Rurais Sem Terra (MST) e assentados da reforma agrária. 2011. 319 f. Tese (Doutorado em Engenharia Agrícola) - Faculdade de Engenharia Agrícola, Universidade Estadual de Campinas, Campinas. 2011.

FAO - ORGANIZAÇÃO DAS NAÇÕES UNIDAS PARA ALIMENTAÇÃO E AGRICULTURA. El estado de la seguridad alimentaria y la nutrición en el mundo. Fomentando la resiliencia climática en aras de la seguridad alimentaria y la nutrición. 2018. Disponível em: www.fao.org/3/I9553ES/i9553es.pdf. Acesso em: 28 nov. 2019.

FURTADO, C. Análise do modelo brasileiro. 8. ed. São Paulo: Civilização Brasileira, 1986. GRZYBOWSKI, C. Movimentos populares no Brasil: desafios e perspectivas. In: STÉDILE, J. P. (org.). A questão agrária hoje. Porto Alegre: Editora UFRGS, 2004. p. 285-295.

IBGE - INSTITUTO BRASILEIRO DE GEOGRAFIA E ESTATÍSTICA. Senso Agropecuário 2017. Disponível em: https://sidra.ibge.gov.br/pesquisa/censoagropecuario/censo-agropecuario-2017. Acesso em: 29 nov. 2019.

KAGEYAMA, A. A questão agrária brasileira: interpretações clássicas. Revista Reforma Agrária. Revista da ABRA, Rio de Janeiro, v. 23, n. 3, set./dez. 1993. Disponível em: http://docvirt.com/docreader.net/DocReader.aspx?bib=hemerolt\&pagfis=11815. Acesso em: 15 jan. 2020.

LINHARES, M. Y.L.; SILVA, F. C.T. Terra prometida: uma história da questão agrária no Brasil. Rio de Janeiro: Campus, 1999. 
MOREIRA, R. J. Críticas ambientais à Revolução Verde. Estudos Sociedade e Agricultura, Rio de Janeiro, v. 8, n. 2, out. 2000.

SILVA, J. G. da. Nova dinâmica da agricultura brasileira. Campinas: Editora Unicamp, 1996. 